\title{
Effect of genotype and overfeeding on lipid deposition in myofibres and intramuscular adipocytes of breast and thigh muscles of ducks
}

\author{
Pascal CHARTRIN ${ }^{\mathrm{a} *}$, Achille SCHIAVONE $^{\mathrm{b}}$, Marie Dominique BERNADET ${ }^{\mathrm{c}}$, \\ Gérard GUYc, Jacques MOUROT ${ }^{\mathrm{d}}$, Michel J. DUCLOS ${ }^{\mathrm{a}}$, Elisabeth BAÉZA ${ }^{\mathrm{a}}$ \\ a Station de Recherches Avicoles, INRA Tours, 37380 Nouzilly, France \\ b Dipartimento di Produzioni Animali, Epidemiologia ed Ecologia, 10095 Grugliasco (TO), Italy \\ c SEPFG, INRA Artiguères, 40280 Benquet, France \\ d URVMP, INRA, 35590 St Gilles, France
}

(Received 21 September 2004; accepted 15 November 2004)

\begin{abstract}
We conducted a study to evaluate the effects of genotype (Muscovy, Pekin and their crossbred, hinny and mule) and overfeeding (14 days from 12 weeks of age) on lipid deposition in myofibres and intramuscular adipocytes of breast and thigh muscles of ducks. Birds of the four genotypes were also reared contemporaneously with a growing diet distributed ad libitum. Muscle samples (Pectoralis major and Sartorius) were collected at 14 weeks of age on 8 ducks per treatment. The muscle fibre typing, the total lipid and triglyceride contents in myofibres and the relative surface occupied by adipocytes on the cross-sectional area of the muscles were determined by histological and image analysis. Overfeeding induced a marked increase of body weight but had no significant effect on the muscle weight, the cross-sectional area (CSA) of myofibres and the muscle typology. In muscles, overfeeding induced a large accumulation of lipids, mainly in adipocytes whose relative surface increased 1.5 fold in P. major and 2.1 fold in Sartorius and an increase in triglyceride content of fast twitch oxydo-glycolytic and glycolytic fibres in $P$. major only (+37 and $+16 \%$ respectively). Genotype had no significant effect on the muscle typology. By comparison with the other genotypes, Muscovy ducks exhibited the highest body weight, the highest muscle weight which could partly be explained by the highest fibre CSA and the lowest intramuscular fat content in adipocytes and myofibres (only fast twitch oxydo-glycolytic fibres in $P$. major). We observed the reverse situation for the Pekin ducks. The crossbred ducks always presented intermediate values except for body weight.
\end{abstract}

lipids / myofibres / adipocytes / muscles / ducks

\section{INTRODUCTION}

In bovines [1] and rabbits [2] it has been demonstrated that intramuscular fat (IMF) was stored both in the myofibres and between the fasciculi, in adipocytes. In bovines [3], pigs [4] and rabbits [22], the IMF increase in muscles results mainly from hypertrophy and hyperplasia of adipocytes. Lipid content in poultry meat is low, particularly in the breast meat of chicken (around $1 \mathrm{~g}$ per $100 \mathrm{~g}$ of meat, [5]) but can be manipulated

\footnotetext{
* Corresponding author: chartrin@ tours.inra.fr
} 
Table I. Main characteristics of feed for rearing and overfeeding periods. Preparation for overfeeding contained corn (25\%), corn meal (35\%) and water $(40 \%)$.

\begin{tabular}{lccc}
\hline Characteristics & $\begin{array}{c}\text { Starting } \\
(0-4 \text { weeks })\end{array}$ & $\begin{array}{c}\text { Growing } \\
(4-12 \text { weeks })\end{array}$ & $\begin{array}{c}\text { Overfeeding } \\
(12-14 \text { weeks })\end{array}$ \\
\hline ME kcal $\cdot \mathrm{kg}^{-1 *}$ & 2830 & 2850 & 3330 \\
CP $(\%)$ & 18.21 & 15.98 & 8.28 \\
Lipids (\%) & 3.34 & 2.84 & 3.38 \\
SFA (\%) & 17.17 & 16.10 & 14.52 \\
MUFA (\%) & 24.98 & 28.36 & 27.44 \\
PUFA (\%) & 57.85 & 55.54 & 58.02 \\
\hline
\end{tabular}

* Calculated value for metabolisable energy (ME); CP = crude protein; SFA, MUFA, PUFA = saturated, mono-unsaturated and poly-unsatured fatty acids.

to a large extent by different factors: species, age, sex, nutrition and selection [5]. In addition, muscles which differ in their contractile and metabolic properties are not homogeneous with regards to their final lipid content [5]. However, until now, the localisation of IMF in poultry, has received little attention. By using different duck genotypes (Pekin, Muscovy and their crossbred, hinny and mule) presenting different susceptibilities for the storage of lipids in the liver or in peripheral tissues such as adipose tissues and muscles during an overfeeding period [6,7], we were able to obtain a wide range of lipid content in meat [8]: 2.3 to $7.6 \mathrm{~g}$ per $100 \mathrm{~g}$ of breast meat (Pectoralis major) and 2.2 to 5.7 per $100 \mathrm{~g}$ of thigh meat (Iliotibialis superficialis). Pekin ducks showed a much marked extra-hepatic fattening (in adipose and muscle tissues) and, at the extreme, Muscovy ducks exhibited a much marked steatosis and the lowest lipid deposition in adipose tissues and muscles. In France, the most commonly used species are mule and Muscovy ducks. By using Pekin and hinny ducks, we were able to generate a higher variability in muscle lipid content. Therefore, it seemed interesting to use this model to determine the localisation of IMF in duck muscles in relationship with their final lipid content and fibre type composition: Pectoralis major (a breast muscle) and Sartorius (a thigh muscle).

\section{MATERIALS AND METHODS}

\subsection{Bird management}

We used male ducks from four different genotypes: Pekin (Anas platyrhynchos), Muscovy (Cairina moschata) and their crossbred, mule (male Muscovy duck $\times$ female Pekin duck) and hinny (male Pekin duck $\times$ female Muscovy duck). The ducks (50 per genotype) were issued from the same sires and dams provided by the Grimaud Company (Roussay, France). They were reared under natural conditions of light and temperature at the Experimental Station for Waterfowl Breeding (INRA Artiguères, France). From hatching to 6 weeks of age, they were fed ad libitum. From 6 to 12 weeks of age, they were fed on a restricted diet at levels appropriate for each genotype (200-250 g per duck at the beginning, increasing to 360 $380 \mathrm{~g}$ at the end of the period [8]). At 12 weeks of age, 35 ducks per genotype were overfed at the maximum of their ingestion potential for 14 days with corn and corn meal. During the overfeeding period, 12 ducks per genotype were kept ad libitum with the growing diet (controls). The main characteristics of diets (starting, growing and overfeeding) are shown in Table I.

At 14 weeks of age, 8 ducks per genotype and randomly chosen dietary treatment were 
weighed and sacrificed by sectioning of the neck. Immediately after bleeding, a breast (Pectoralis major) and a thigh muscle (Sartorius) were excised and weighed. One sample of $P$. major and the whole Sartorius were quickly frozen in isopentane cooled with liquid nitrogen and stored at $-80{ }^{\circ} \mathrm{C}$ until histochemical analysis was performed as previously described by Baéza et al. [9].

The present work was carried out in agreement with French legislation on animal experimentation and with the authorisation of the French Ministry of Agriculture (Animal Health and Protection Directorate).

\subsection{Histological analysis}

Serial cross-sections, $12 \mu \mathrm{m}$ thick, were obtained at $-20^{\circ} \mathrm{C}$ in a cryostat (Jung Frigocut 2800N, Leica, Rueil-Malmaison, France). Six serial cross-sections per bird were prepared to evaluate the size, the typology and the lipid content of myofibres. Fibre types were determined on the basis of their ATPase activity after preincubation at $\mathrm{pH}$ 4.10 and 10.50 [10] and their succinate dehydrogenase (SDH) activity [11]. Myofibres were classified as type $\beta \mathrm{R}$ and $\alpha$ according to the terminology of Ashmore and Doerr [11]. Slow-twitch fibres (type $\beta R$ ) were identified as being stable after acid preincubation and labile after alkaline preincubation, while fast-twitch fibres (type $\alpha$ ) were labile after acid preincubation and stable after alkaline preincubation. SDH staining made it possible to characterise fibres with high oxidative activity (deep blue granulation, types $\alpha r$ and $\beta r$ ) and low oxidative activity (pale blue stained fibres, type $\alpha \mathrm{W}$ ). The Sartorius muscle can be divided into a fast portion (superficial) composed of type $\alpha r$ and $\alpha \mathrm{w}$ fibres and a mixed portion (deep) composed of type $\beta \mathrm{R}, \alpha \mathrm{R}$ and $\alpha \mathrm{W}$ fibres [12]. We only studied the mixed portion which represents the third part of a muscle cross-section after ATPase activity determination. One other section of the muscle was stained with red azorubin, which permits clear identification of the interfibre net- work by staining only myofibres in red, and it was named the reference stain. Percentage and mean cross-sectional area (CSA) of each fibre type were determined using a computerised image analysis system [13]. For image acquisition and treatment, the software, called RACINE, was implemented on a UNIX workstation equipped with a graphic card linked with a CCD video camera placed on a microscope (Leica DMRB, Leica, RueilMalmaison, France).

Triglycerides and total lipids were differentially stained in myofibres with Red oil (RO) and Sudan black (SB) according to Koopman et al. [14] and Dubowitz [15], respectively. RO and SB stain intensities were measured on individual myofibres as the mean pixel luminance determined from 100 pixels located around the central area of the fibres, expressed on a 256 grey level scale. Triglycerides and total lipids on each sample and for one given fibre type were determined photometrically from luminance measurements according to the following formula: $\Sigma \mathrm{Li} \mathrm{Si} / \Sigma \mathrm{Si}$, where $\mathrm{Li}$ and $\mathrm{Si}$ were the average RO or SB staining luminance and the cross sectional area of the ith fibre, respectively, and named Lc RO and Lc SB according to Fernandez et al. [16]. Luminance was negatively correlated with a lipid presence.

All these variables were determined for approximately 200 fibres for each muscle.

To evaluate the relative surface occupied by adipocytes on the cross-sectional area of each muscle sample, three serial cross-sections were prepared. Oil Red 0 was used to stain, in red/orange, the clusters of adipocytes according to Dubowitz [15]. To calculate the mean relative area of clusters of adipocytes three microscopic fields $\left(0.92 \mathrm{~mm}^{2}\right)$ around a blood vessel (the only localisation for lean birds) were randomly chosen for each section. The measurements were carried out on the three serial cross-sections for the same microscopic field after image digitalisation and evaluation with VISILOG software (Noesis, Courtabœuf, France). The results were expressed as the relative 
Table II. Effects of genotype and overfeeding on body weight and weight of Pectoralis major and Sartorius muscles of ducks (means $\pm \mathrm{SEM}, n=8$ ).

\begin{tabular}{lcccc}
\hline Genotypes & Feeding plan & Body weight $(\mathrm{g})$ & P. major weight $(\mathrm{g})$ & Sartorius weight $(\mathrm{g})$ \\
\hline & Overfed & $6295 \pm 369 \mathrm{a}$ & $303 \pm 33$ & $9.20 \pm 1.00$ \\
& Control & $4838 \pm 380 \mathrm{~b}$ & $297 \pm 29$ & $9.66 \pm 0.90$ \\
Overfeeding effect & & $* * *$ & $\mathrm{~ns}$ & $\mathrm{~ns}$ \\
Muscovy & & $5905 \pm 345 \mathrm{a}$ & $403 \pm 43 \mathrm{a}$ & $11.64 \pm 1.37 \mathrm{a}$ \\
Hinny & & $5585 \pm 436 \mathrm{~b}$ & $293 \pm 27 \mathrm{~b}$ & $9.65 \pm 0.94 \mathrm{~b}$ \\
Mule & $5464 \pm 359 \mathrm{~b}$ & $294 \pm 28 \mathrm{~b}$ & $9.65 \pm 0.67 \mathrm{~b}$ \\
Pekin & & $5311 \pm 378 \mathrm{~b}$ & $212 \pm 26 \mathrm{c}$ & $6.78 \pm 0.72 \mathrm{c}$ \\
Genotype effect & & $* * *$ & $* * *$ & $* * *$ \\
Muscovy & Overfed & $6393 \pm 441 \mathrm{a}$ & $408 \pm 49$ & $10.92 \pm 1.56$ \\
& Control & $5418 \pm 245 \mathrm{~b}$ & $398 \pm 39$ & $12.37 \pm 1.27$ \\
Hinny & Overfed & $6315 \pm 402 \mathrm{a}$ & $290 \pm 25$ & $9.68 \pm 0.87$ \\
& Control & $4854 \pm 497 \mathrm{c}$ & $297 \pm 29$ & $9.63 \pm 1.06$ \\
Mule & Overfed & $6473 \pm 351 \mathrm{a}$ & $309 \pm 28$ & $9.74 \pm 0.69$ \\
& Control & $4455 \pm 392 \mathrm{c}$ & $278 \pm 30$ & $9.56 \pm 0.69$ \\
Pekin & Overfed & $5999 \pm 353 \mathrm{a}$ & $208 \pm 33$ & $6.47 \pm 0.87$ \\
& Control & $4623 \pm 426 \mathrm{c}$ & $216 \pm 18$ & $7.08 \pm 0.59$ \\
Interaction effect & & $* *$ & $\mathrm{~ns}$ & $\mathrm{~ns}$ \\
\hline
\end{tabular}

$*, * *, * * *$ Significant effect with $P<0.05, P<0.01$ or $P<0.001$; ns = no significant; a,b,c: significant difference between groups for one criterion.

surface occupied by adipocyte cluster per observed field $(\%)$.

\subsection{Statistical analysis}

Data were analysed by analysis of variance using the General Linear Model procedure of SAS [17]. The model included the main effects of genotype, feeding plan and their interaction. Among the different groups, significant differences between means were shown according to the Newman-Keul test. We also calculated coefficient correlations of Pearson and regression equations between the relative surface occupied by adipocytes in the cross-sectional area of $P$. major muscles, the average of luminance values in each fibre type for total lipid and triglycerides and the total lipid and triglyceride contents in the same samples previously determined by chemical analysis with the same experimental design [8].

\section{RESULTS}

Overfeeding induced a large increase in body weight $(+30 \%)$ but had no significant effect on muscle weight (Tab. II). Body weight increase was about $45 \%$ for mule ducks, $30 \%$ for hinny and Pekin ducks and $18 \%$ for Muscovy ducks.

By comparison with the other genotypes, Muscovy ducks exhibited significantly higher body and muscle weights (Tab. II). Pekin ducks exhibited the lowest muscle weight. Mule and hinny ducks showed intermediate values.

Overfeeding induced a highly significant increase in the relative surface occupied by adipocytes on cross sections of $P$. major (3.74 \pm 0.77 vs. $2.45 \pm 0.49 \%$ in ad libitum ducks) and Sartorius (3.72 \pm 1.08 vs. $1.80 \pm$ $0.46 \%$ in ad libitum ducks) muscles (Tab. III).

The relative surface occupied by adipocytes in the cross-sectional area of the 
Table III. Effects of genotype and overfeeding on the relative surface occupied by adipocytes on cross-sections of Sartorius and Pectoralis major muscles of ducks (means \pm SEM, $n=8$ ).

\begin{tabular}{lccc}
\hline Genotypes & Feeding plan & Surface $(\%)$ in Sartorius & Surface (\%) in P. major \\
\hline & Overfed & $3.72 \pm 1.08 \mathrm{a}$ & $3.74 \pm 0.77 \mathrm{a}$ \\
& Control & $1.80 \pm 0.46 \mathrm{~b}$ & $2.45 \pm 0.49 \mathrm{~b}$ \\
Overfeeding effect & & $* * *$ & $* * *$ \\
Muscovy & & $1.73 \pm 0.45 \mathrm{c}$ & $1.57 \pm 0.35 \mathrm{c}$ \\
Hinny & & $2.75 \pm 0.56 \mathrm{~b}$ & $3.10 \pm 0.69 \mathrm{~b}$ \\
Mule & & $3.79 \pm 0.85 \mathrm{~b}$ & $3.06 \pm 0.78 \mathrm{~b}$ \\
Pekin & & $* * * 28 \mathrm{a}$ & $4.66 \pm 0.72 \mathrm{a}$ \\
Genotype effect & & $2.40 \pm 0.53 \mathrm{c}$ & $* * *$ \\
Muscovy & Overfed & $1.07 \pm 0.39 \mathrm{~d}$ & $1.98 \pm 0.39 \mathrm{c}$ \\
& Control & $3.63 \pm 0.68 \mathrm{~b}$ & $1.15 \pm 0.34 \mathrm{~d}$ \\
Hinny & Overfed & $1.88 \pm 0.45 \mathrm{~cd}$ & $3.74 \pm 0.95 \mathrm{~b}$ \\
& Control & $3.58 \pm 1.15 \mathrm{~b}$ & $2.47 \pm 0.34 \mathrm{c}$ \\
Mule & Overfed & $2.00 \pm 0.46 \mathrm{~cd}$ & $3.52 \pm 0.94 \mathrm{~b}$ \\
& Control & $5.27 \pm 1.77 \mathrm{a}$ & $2.60 \pm 0.66 \mathrm{c}$ \\
Pekin & Overfed & $2.26 \pm 0.60 \mathrm{c}$ & $5.73 \pm 0.85 \mathrm{a}$ \\
& Control & $*$ & $3.59 \pm 0.62 \mathrm{~b}$ \\
Interaction effect & & $* 1.76$ & $*$ \\
\hline
\end{tabular}

*, **,*** Significant effect with $P<0.05, P<0.01$ or $P<0.001$; ns = no significant; a,b,c: significant difference between groups for one criterion.

muscle was the highest in Pekin ducks $(3.76 \pm 1.28 \%$ and $4.66 \pm 0.72 \%$ in Sartorius and $P$. major respectively) and the lowest in Muscovy ducks $(1.73 \pm 0.45 \%$ and $1.57 \pm 0.35 \%$ in Sartorius and P. major respectively, Tab. III).

In control birds, the relative surface occupied by adipocytes was higher in P. major than in Sartorius: $2.45 \%$ vs. $1.80 \%$ (Tab. III). In overfed birds it was higher in Sartorius than in P. major for Muscovy ducks and equivalent in both muscles for the other genotypes.

In $P$. major muscle, the mean percentages of type $\alpha \mathrm{R}$ and $\alpha \mathrm{W}$ fibres were 86 and $14 \%$, respectively. In Sartorius, the mean percentages of type $\beta \mathrm{R}, \alpha \mathrm{R}$ and $\alpha \mathrm{W}$ fibres were 12 , 52 and $36 \%$ respectively. Overfeeding had no significant effect on typology (data not shown) and size (CSA) of fibres in P. major and Sartorius muscles (Tabs. IV and V).

Genotype had no significant effect on the typology of fibres (data not shown). In
P. major muscle, the average CSA of type $\alpha \mathrm{R}$ fibres was significantly higher in Muscovy ducks than in mule and Pekin ducks: $929 \pm 200$ vs. $720 \pm 133 \mu \mathrm{m}^{2}$ and $683 \pm$ $248 \mu \mathrm{m}^{2}$, respectively (Tab. IV). Genotype had no significant effect on the mean CSA of type $\alpha \mathrm{W}$ fibres whose size was higher than that of type $\alpha \mathrm{R}$ fibres (2.3 fold). In the Sartorius muscle, the mean CSA of type $\alpha \mathrm{W}$ fibres was significantly higher in Muscovy ducks than in the other genotypes: $2193 \pm 767 \mu \mathrm{m}^{2}$ vs. $1651 \pm 383 \mu \mathrm{m}^{2}$ in Pekin ducks (Tab. V). Genotype had no significant effect on the mean CSA of type $\beta R$ and $\alpha \mathrm{R}$ fibres. The mean CSA of type $\alpha \mathrm{W}$ fibres was 1.5 and 1.9 fold higher than the mean CSA of type $\beta \mathrm{R}$ and $\alpha \mathrm{R}$ fibres respectively.

The mean CSA of type $\alpha \mathrm{R}$ fibres was higher in Sartorius than in P. major (+27\%). The mean CSA of type $\alpha \mathrm{w}$ fibres was equivalent in both muscles.

In P. major muscle, overfeeding had no significant effect on the total lipid content 
Table IV. Effects of genotype and overfeeding on cross-sectional area (CSA) of fibres and on luminance due to the presence of triglycerides (Lc RO) or total lipid (Lc SB) in fibres of Pectoralis major muscle of ducks (means \pm SEM, $n=8$ ).

\begin{tabular}{|c|c|c|c|c|c|c|c|}
\hline \multirow{2}{*}{\multicolumn{2}{|c|}{$\begin{array}{c}\text { Genotypes Feeding } \\
\text { plan }\end{array}$}} & \multicolumn{3}{|c|}{ Fibres $\alpha \mathrm{R}$} & \multicolumn{3}{|c|}{ Fibres $\alpha \mathrm{W}$} \\
\hline & & $\mathrm{CSA}\left(\mu \mathrm{m}^{2}\right)$ & LC SB & Lc RO & $\operatorname{CSA}\left(\mu \mathrm{m}^{2}\right)$ & LC SB & Lc RO \\
\hline & Overfed & $764 \pm 252$ & $97 \pm 23$ & $96 \pm 22 b$ & $1769 \pm 518$ & $128 \pm 19$ & $140 \pm 18 b$ \\
\hline & Control & $811 \pm 170$ & $106 \pm 21$ & $152 \pm 29 a$ & $1885 \pm 592$ & $132 \pm 26$ & $166 \pm 28 \mathrm{a}$ \\
\hline \multicolumn{2}{|c|}{ Overfeeding effect } & $\mathrm{ns}$ & $\mathrm{ns}$ & $*$ & $\mathrm{~ns}$ & $\mathrm{~ns}$ & $* * *$ \\
\hline \multicolumn{2}{|c|}{ Muscovy } & $929 \pm 200 \mathrm{a}$ & $101 \pm 22$ & $137 \pm 24 \mathrm{a}$ & $2028 \pm 644$ & $126 \pm 25$ & $158 \pm 24$ \\
\hline \multicolumn{2}{|l|}{ Hinny } & $817 \pm 269 \mathrm{ab}$ & $101 \pm 21$ & $111 \pm 29 b$ & $1886 \pm 557$ & $132 \pm 19$ & $147 \pm 25$ \\
\hline \multicolumn{2}{|l|}{ Mule } & $720 \pm 133 b$ & $104 \pm 25$ & $132 \pm 26 a b$ & $1785 \pm 546$ & $132 \pm 27$ & $160 \pm 22$ \\
\hline \multicolumn{2}{|l|}{ Pekin } & $683 \pm 248 b$ & $99 \pm 22$ & $115 \pm 26 \mathrm{ab}$ & $1608 \pm 507$ & $130 \pm 21$ & $146 \pm 24$ \\
\hline \multicolumn{2}{|c|}{ Genotype effect } & $*$ & ns & $* * *$ & ns & ns & ns \\
\hline \multirow[t]{2}{*}{ Muscovy } & Overfed & $908 \pm 250$ & $94 \pm 22$ & $113 \pm 26$ & $1978 \pm 660$ & $121 \pm 23$ & $145 \pm 22$ \\
\hline & Control & $951 \pm 152$ & $107 \pm 23$ & $160 \pm 23$ & $2077 \pm 672$ & $131 \pm 29$ & $172 \pm 28$ \\
\hline \multirow[t]{2}{*}{ Hinny } & Overfed & $787 \pm 345$ & $100 \pm 24$ & $85 \pm 20$ & $1691 \pm 448$ & $133 \pm 17$ & $134 \pm 21$ \\
\hline & Control & $848 \pm 190$ & $102 \pm 19$ & $137 \pm 38$ & $2081 \pm 681$ & $131 \pm 22$ & $159 \pm 30$ \\
\hline \multirow[t]{2}{*}{ Mule } & Overfed & $707 \pm 124$ & $98 \pm 27$ & $100 \pm 20$ & $1902 \pm 594$ & $130 \pm 26$ & $147 \pm 16$ \\
\hline & Control & $732 \pm 151$ & $111 \pm 25$ & $164 \pm 32$ & $1669 \pm 535$ & $134 \pm 30$ & $173 \pm 28$ \\
\hline \multirow[t]{2}{*}{ Pekin } & Overfed & $653 \pm 291$ & $96 \pm 25$ & $84 \pm 28$ & $1505 \pm 445$ & $128 \pm 14$ & $134 \pm 15$ \\
\hline & Control & $712 \pm 216$ & $102 \pm 21$ & $145 \pm 27$ & $1711 \pm 594$ & $131 \pm 28$ & $159 \pm 31$ \\
\hline \multicolumn{2}{|c|}{ Interaction effect } & ns & $\mathrm{ns}$ & ns & $\mathrm{ns}$ & $\mathrm{ns}$ & $\mathrm{ns}$ \\
\hline
\end{tabular}

$*, * *, * * *$ Significant effect with $P<0.05, P<0.01$ or $P<0.001 ; \mathrm{ns}=$ no significant; a,b,c: significant difference between groups for one criterion.

Lc SB and Lc RO: luminances due to the staining with Sudan black (total lipids) and Red oil (triglycerides). Fibres $\alpha \mathrm{R}$ and $\alpha \mathrm{W}$ : fast-twitch fibres, oxydo-glycolytic and glycolytic respectively.

of fibres (Tab. IV) but, it induced an increase in the triglyceride content of type $\alpha \mathrm{R}$ and $\alpha \mathrm{W}$ fibres: +37 and $+16 \%$, respectively. In Sartorius muscle, overfeeding induced a decrease in total lipid and triglyceride content of all fibre types: -18 and $-12 \%$ in type $\beta \mathrm{R}$ fibres, -18 and $-17 \%$ in type $\alpha \mathrm{R}$ fibres and -18 and $-14 \%$ in type $\alpha \mathrm{W}$ fibres, respectively (Tab. V).

In $P$. major muscle, genotype only had a significant effect on the triglyceride content of type $\alpha \mathrm{R}$ fibres which was lower in Muscovy ducks in comparison with the other genotypes (average luminance of 137 vs. 111,132 and 115 in hinny, mule and Pekin ducks respectively). In Sartorius muscle, genotype had no significant effect on the triglyceride and total lipid content of the fibres.
The triglyceride and total lipid content of type $\alpha \mathrm{R}$ and $\alpha \mathrm{W}$ fibres was significantly lower $(P<0.05)$ in Sartorius than in $P$. major.

Using data reported by Chartrin et al. [8], we calculated correlations between total lipid (g per $100 \mathrm{~g}$ of muscle) and triglyceride content (\% of total lipid) or the quantity of triglycerides in muscle ( $\mathrm{g}$ per $100 \mathrm{~g}$ of muscle) and the relative surface occupied by adipocytes on muscle microscopic fields of all ducks. In $P$. major, highly significant correlations $(P<0.001)$ were observed in all cases with $r$ values of $0.80,0.78$ and 0.83 respectively (Fig. 1). Significant correlations $(P<0.05)$ were also observed with the average luminance values for the Red oil staining procedure (triglycerides). For type $\alpha \mathrm{R}$ fibres, the $r$ values were $-0.65,-0.65$ and 
Table V. Effects of genotype and overfeeding on cross-sectional area (CSA) of fibres and on luminance due to the presence of triglycerides (Lc RO) or total lipid (Lc SB) in fibres of Sartorius muscle of ducks (means $\pm \mathrm{SEM}, n=8$ ).

\begin{tabular}{|c|c|c|c|c|c|c|c|c|c|c|}
\hline \multirow[t]{2}{*}{ Genotypes } & \multirow[t]{2}{*}{ Feeding plan } & \multicolumn{3}{|c|}{ Fibres $\beta R$} & \multicolumn{3}{|c|}{ Fibres $\alpha \mathrm{R}$} & \multicolumn{3}{|c|}{ Fibres $\alpha \mathrm{W}$} \\
\hline & & $\operatorname{CSA}\left(\mu \mathrm{m}^{2}\right)$ & LC SB & Lc RO & $\operatorname{CSA}\left(\mu \mathrm{m}^{2}\right)$ & LC SB & Lc RO & $\operatorname{CSA}\left(\mu \mathrm{m}^{2}\right)$ & LC SB & Lc RO \\
\hline & Overfed & $1232 \pm 329$ & $157 \pm 28 \mathrm{a}$ & $177 \pm 27 \mathrm{a}$ & $1017 \pm 223$ & $150 \pm 29 a$ & $177 \pm 26 \mathrm{a}$ & $1980 \pm 611$ & $162 \pm 30 a$ & $182 \pm 27 \mathrm{a}$ \\
\hline & Control & $1320 \pm 439$ & $134 \pm 18 b$ & $159 \pm 18 b$ & $975 \pm 180$ & $127 \pm 17 b$ & $151 \pm 17 b$ & $1738 \pm 484$ & $137 \pm 19 b$ & $160 \pm 19 b$ \\
\hline \multicolumn{2}{|c|}{ Overfeeding effect } & ns & $* * *$ & $* *$ & ns & $* * *$ & $* * *$ & ns & $* * *$ & $* * *$ \\
\hline \multicolumn{2}{|l|}{ Muscovy } & $1355 \pm 357$ & $142 \pm 23$ & $168 \pm 25$ & $1105 \pm 145$ & $137 \pm 22$ & $164 \pm 26$ & $2193 \pm 760 a$ & $147 \pm 23$ & $172 \pm 27$ \\
\hline \multicolumn{2}{|l|}{ Hinny } & $1340 \pm 394$ & $150 \pm 21$ & $173 \pm 22$ & $993 \pm 192$ & $144 \pm 22$ & $169 \pm 20$ & $1737 \pm 560 \mathrm{~b}$ & $149 \pm 23$ & $171 \pm 23$ \\
\hline \multicolumn{2}{|l|}{ Mule } & $1164 \pm 411$ & $148 \pm 26$ & $164 \pm 23$ & $891 \pm 214$ & $138 \pm 29$ & $161 \pm 19$ & $1856 \pm 439 b$ & $150 \pm 26$ & $170 \pm 18$ \\
\hline \multicolumn{2}{|l|}{ Pekin } & $1245 \pm 413$ & $143 \pm 23$ & $167 \pm 24$ & $996 \pm 256$ & $136 \pm 24$ & $162 \pm 25$ & $1651 \pm 415 b$ & $150 \pm 28$ & $171 \pm 27$ \\
\hline \multicolumn{2}{|c|}{ Genotype effect } & ns & ns & ns & $\mathrm{ns}$ & ns & ns & $*$ & ns & ns \\
\hline \multirow[t]{2}{*}{ Muscovy } & Overfed & $1398 \pm 327$ & $150 \pm 29$ & $178 \pm 33$ & $1134 \pm 152$ & $144 \pm 28$ & $177 \pm 34$ & $2356 \pm 945$ & $156 \pm 29$ & $183 \pm 35$ \\
\hline & Control & $1311 \pm 408$ & $134 \pm 18$ & $157 \pm 17$ & $1075 \pm 147$ & $129 \pm 15$ & $152 \pm 17$ & $2029 \pm 588$ & $138 \pm 18$ & $160 \pm 18$ \\
\hline \multirow[t]{2}{*}{ Hinny } & Overfed & $1282 \pm 350$ & $162 \pm 25$ & $177 \pm 23$ & $989 \pm 206$ & $159 \pm 27$ & $176 \pm 24$ & $1851 \pm 657$ & $164 \pm 23$ & $178 \pm 23$ \\
\hline & Control & $1399 \pm 459$ & $138 \pm 19$ & $170 \pm 21$ & $996 \pm 190$ & $130 \pm 17$ & $161 \pm 16$ & $1622 \pm 491$ & $134 \pm 25$ & $165 \pm 24$ \\
\hline \multirow[t]{2}{*}{ Mule } & Overfed & $1133 \pm 273$ & $166 \pm 35$ & $174 \pm 29$ & $923 \pm 259$ & $153 \pm 39$ & $178 \pm 21$ & $2158 \pm 544$ & $166 \pm 35$ & $183 \pm 20$ \\
\hline & Control & $1194 \pm 536$ & $130 \pm 17$ & $154 \pm 18$ & $859 \pm 178$ & $123 \pm 14$ & $145 \pm 18$ & $1554 \pm 341$ & $134 \pm 15$ & $157 \pm 17$ \\
\hline \multirow[t]{2}{*}{ Pekin } & Overfed & $1114 \pm 419$ & $152 \pm 27$ & $181 \pm 30$ & $1023 \pm 294$ & $146 \pm 27$ & $177 \pm 29$ & $1554 \pm 187$ & $160 \pm 36$ & $184 \pm 34$ \\
\hline & Control & $1375 \pm 436$ & $134 \pm 20$ & $154 \pm 19$ & $970 \pm 233$ & $126 \pm 23$ & $146 \pm 21$ & $1748 \pm 578$ & $140 \pm 20$ & $158 \pm 20$ \\
\hline
\end{tabular}

$*$,***** Significant effect with $P<0.05, P<0.01$ or $P<0.001$; ns $=$ no significant; a,b,c: significant difference between groups for one criterion.

Lc SB and Lc RO: luminances due to the staining with Sudan black (total lipids) and Red oil (triglycerides).

Fibres $\beta \mathrm{R}$ : oxydative slow-twitch fibres. Fibres $\alpha \mathrm{R}$ and $\alpha \mathrm{W}$ : fast-twitch fibres, oxydo-glycolytic and glycolytic respectively. 

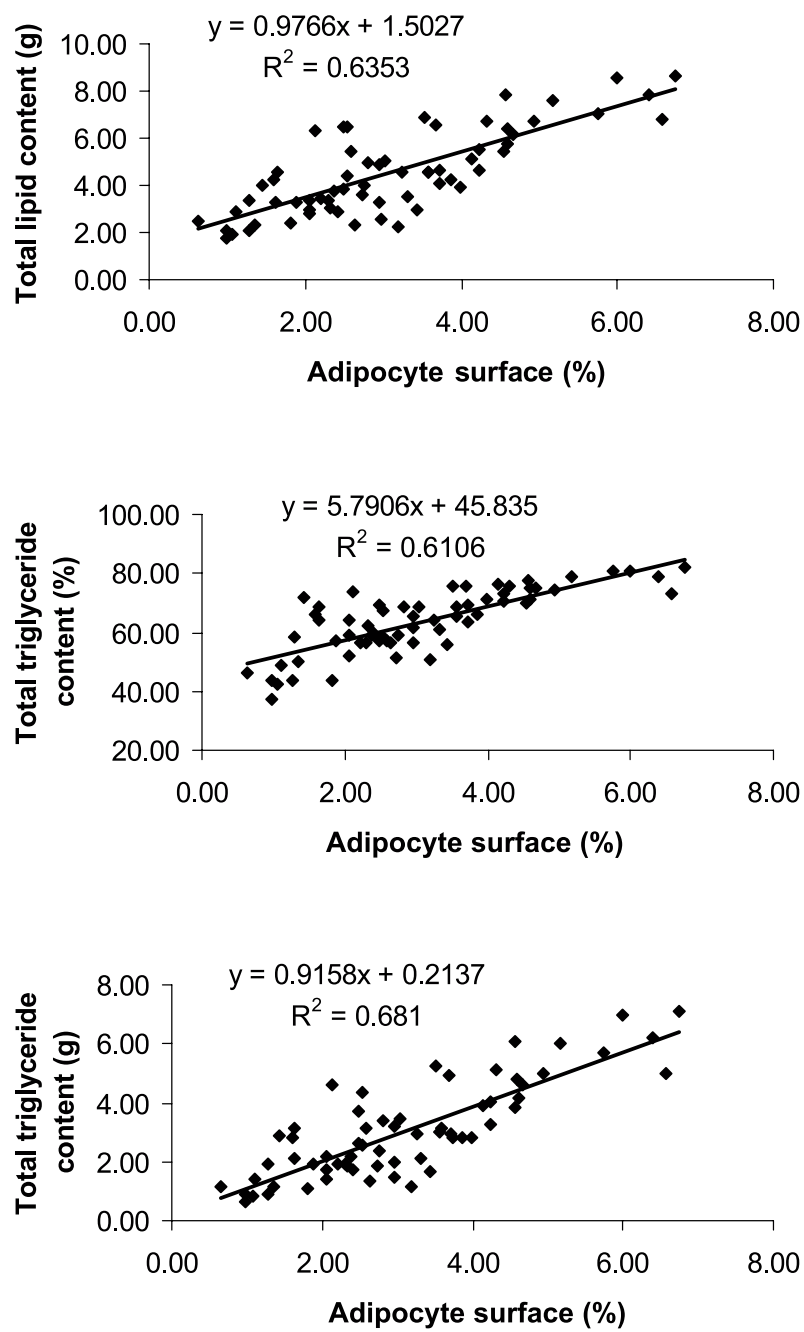

Figure 1. Relationships between the relative surface occupied by adipocytes on muscle cross-sections and the total lipid (g per $100 \mathrm{~g}$ of muscle) and triglyceride (expressed as \% of total lipids or g per $100 \mathrm{~g}$ of muscle) contents in the $P$. major of ducks $(P<0.001)$.

-0.67 respectively (Fig. 2). For type $\alpha \mathrm{W}$ fibres, the $r$ values were lower: $-0.41,-0.44$ and -0.43 respectively (Fig. 3 ).

We also calculated these correlations for each genotype but none was significant (data not shown).

\section{DISCUSSION}

Overfeeding induced a large increase in body weight as previously reported [18, 19]. This resulted from a dramatic increase in the synthesis of lipids in the liver which 

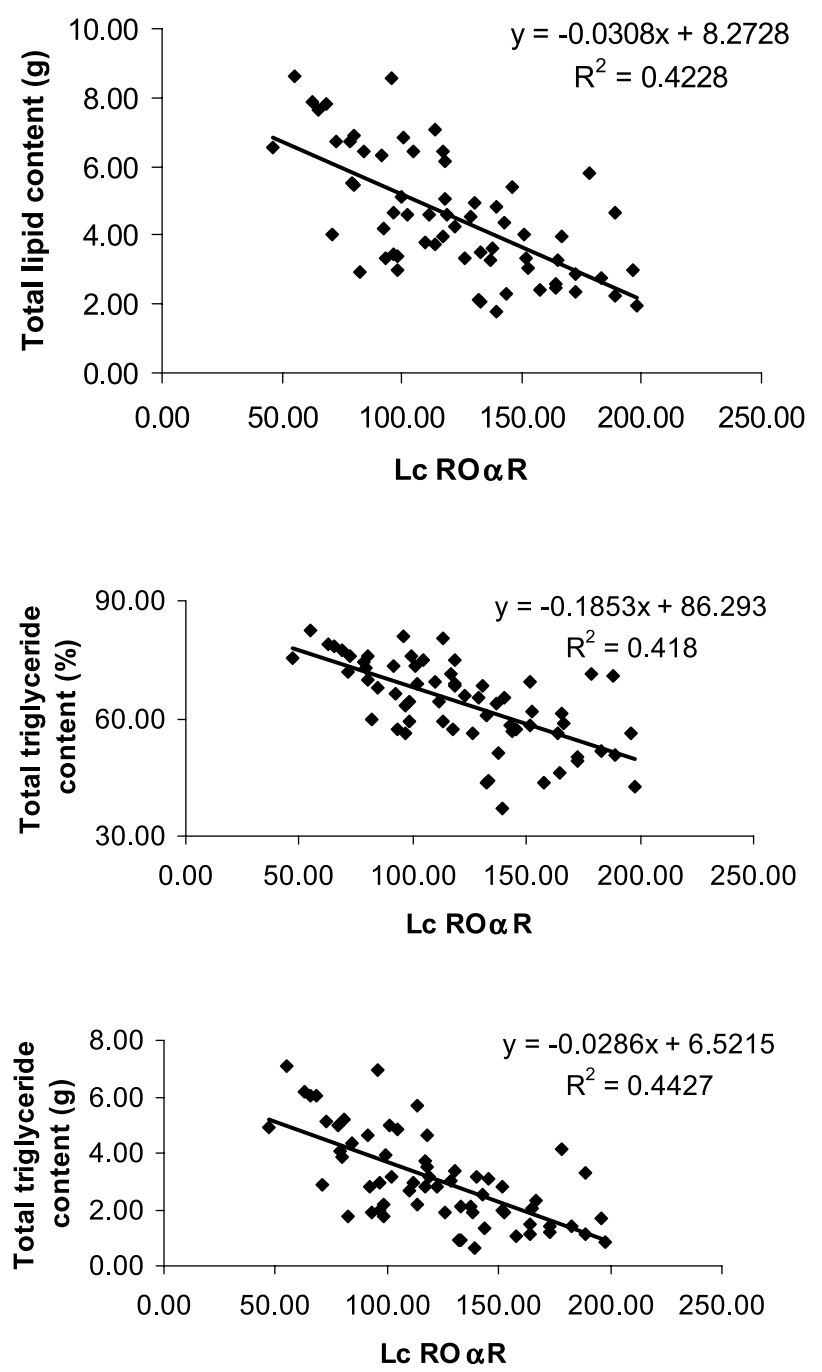

Figure 2. Relationships between the average luminance values for triglycerides in type $\alpha$ r fibres obtained with the Red oil staining procedure (Lc RO $\alpha \mathrm{R}$ ) and the total lipid (g per $100 \mathrm{~g}$ of muscle) and triglyceride (expressed as \% of total lipids or g per $100 \mathrm{~g}$ of muscle) contents in the $P$. major muscle of ducks $(P<0.05)$.

accumulated first in the liver but also in peripheral tissues such as adipose tissues and muscles [6-8]. Accordingly, the lipid content of muscles increased [8,20]: 1.3 to 2.1 fold depending on muscle type and genotype. We observed a large increase in the relative surface occupied by adipocytes on muscle sections: 1.5 fold in P. major and 2.1 fold in Sartorius across genotypes. This confirmed the previous observations of Zanusso et al. [20] obtained in Muscovy ducks. The availability of data across a wide range of muscle lipid concentrations in P. major allowed obtaining high correlations between the relative surface occupied by adipocytes in muscle sections and the total lipid (g per 

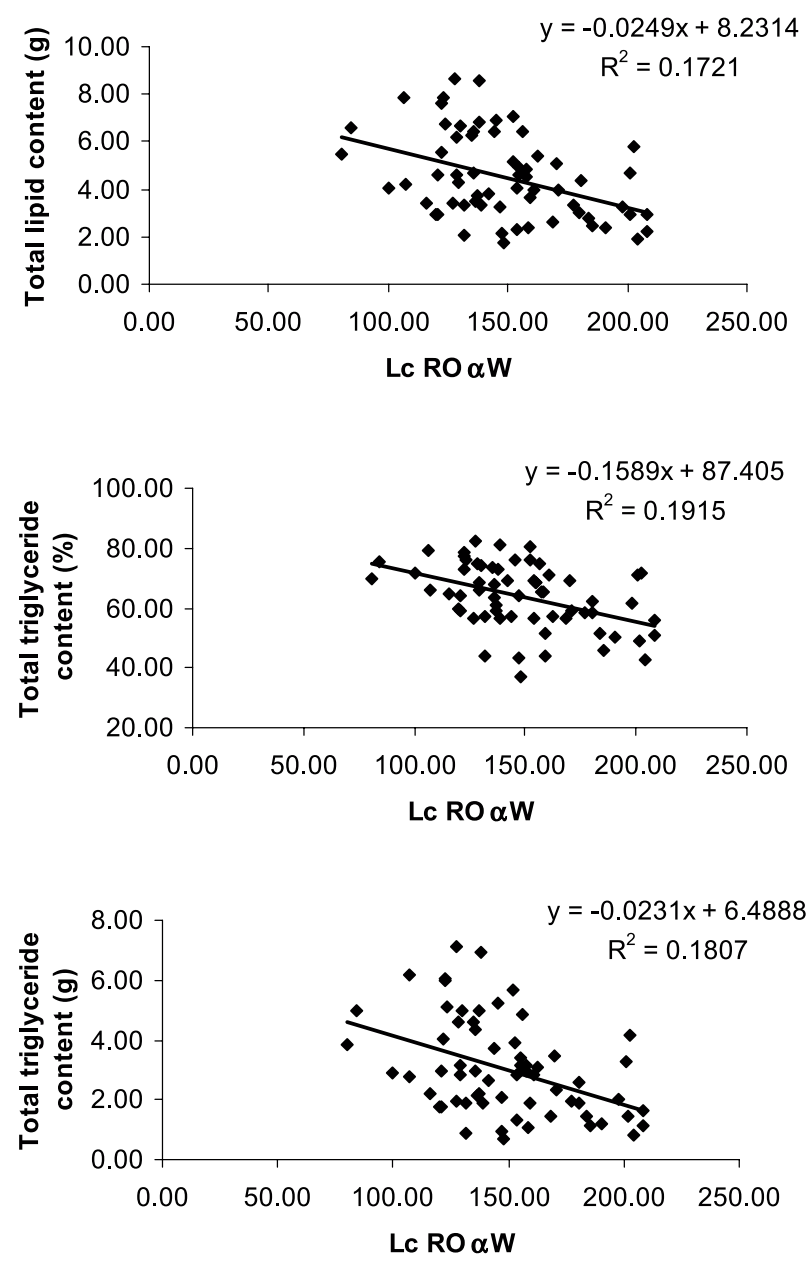

Figure 3. Relationships between the average luminance values for triglycerides in type $\alpha \mathrm{w}$ fibres obtained with the Red oil staining procedure (Lc RO $\alpha \mathrm{W}$ ) and the total lipid (g per $100 \mathrm{~g}$ of muscle) and triglyceride (expressed as \% of total lipids or g per $100 \mathrm{~g}$ of muscle) contents in the P. major muscle of ducks $(P<0.05)$.

$100 \mathrm{~g}$ of muscle) and triglyceride contents (\% of total lipids) or the quantity of triglycerides in this same muscle (g per $100 \mathrm{~g}$ of muscle). In control birds, the relative surface occupied by adipocytes was higher in the Sartorius than in P. major. In overfed birds, we observed the reverse in Muscovy ducks or we had equivalent values between both muscles in the other genotypes. Therefore, the effect of overfeeding on the increase of the relative surface occupied by adipocytes was higher in the Sartorius muscle. In P. major muscle, overfeeding had no significant effect on the total lipid content of muscle fibres (luminance of Sudan black B staining). Zanusso et al. [20] with the same staining procedure also found no significant difference of luminance between control and overfed Muscovy ducks. Inside the fibres, the proportion of phospholipids is 
quite important and stable and could have masked the effect of overfeeding on triglyceride deposition. Actually, in P. major muscle, overfeeding induced an increase in triglyceride (depot lipids) content of type $\alpha r$ muscle fibres which have an oxydo-glycolytic metabolism. Moreover, the average of luminance values in type $\alpha$ r fibres for triglycerides obtained with the Red oil staining procedure and the total lipid ( $\mathrm{g}$ per $100 \mathrm{~g}$ of muscle) and triglyceride content (\% of total lipids) or the quantity of triglycerides in this same muscle (g per $100 \mathrm{~g}$ of muscle) were highly correlated. In Sartorius muscle, overfeeding induced a decrease in total lipid and triglyceride content of muscle fibres. This result was quite surprising and before trying to find an explanation we would like to confirm this observation. The total lipid and triglyceride content of type $\alpha \mathrm{R}$ and $\alpha \mathrm{W}$ muscle fibres was higher in P. major than in Sartorius.

Overfeeding had no significant effect on the weight of muscles and the CSA of muscle fibres. During overfeeding, the growth of $P$. major is reduced or stopped [18, 19]. In the Muscovy duck, Zanusso et al. [20] also showed that the CSA of muscle fibres is not significantly influenced by overfeeding. As Zanusso et al. [20], we found that the composition of fibre type of muscles was not modified by overfeeding. Actually, it is quite difficult to modulate the fibre type composition of muscles. In chickens, a selection for rapid growth does not change muscle fibre typing [21]. In Muscovy ducks, a selection for improved body weight and higher meat yield only modifies the typology of Sartorius muscle which exhibits a higher percentage of type $\alpha \mathrm{W}$ fibres at the expense of type $\alpha \mathrm{R}$ fibres [22] while the typology of $P$. major remains unchanged. In Muscovy ducks, there is a marked dimorphism on body weight which significantly influences muscle weight. Males have much heavier muscles than females but the muscle typology is the same in both sexes [9]. Concerning the effect of nutrition management, many studies have also reported that feed restriction has either no effect on the muscle typology in rats [23], in cattle [24], in pigs [25], in rabbits [26] or increases the percentage of oxidative myofibres in cattle [27], in lambs [28] and in pigs [29].

The original part of this study was the analysis of the genotype effect. Muscovy ducks exhibit the highest body weight, the highest muscle weight and the lowest fattiness in comparison with the other genotypes [6-8]. For these reasons, this species has been chosen in France for the production of duck meat [30]. The difference in muscle weight between the Muscovy duck and the other genotypes $(+72 \%$ and $+90 \%$ for Sartorius and P. major, respectively by comparison with the Pekin duck) could be explained partly by a higher CSA of muscle fibres $(+36 \%$ for type $\alpha \mathrm{W}$ fibres in Sartorius and $+33 \%$ for type $\alpha \mathrm{R}$ fibres in P. major, by comparison with the Pekin duck) but also by a higher number and/or length of muscle fibres. Genotype had no significant effect on the fibre type composition in muscles. Concerning muscle typology, we confirmed previous results obtained by Torrella et al. [12] in mallard ducks, Gille et al. [31] in Pekin ducks, Baéza et al. [9] in Muscovy ducks and Baéza et al. [32] in mule ducks.

Pekin ducks exhibited a higher lipid content in muscles in comparison with the other genotypes $(+105$ and $+120 \%$ in P. major and Iliotibialis superficialis, respectively in comparison with the Muscovy duck, [8]). This data was confirmed by the highest relative surface occupied by adipocytes in $P$. major and Sartorius for Pekin ducks $(+117$ and $+197 \%$ in Sartorius and P. major, respectively by comparison with the Muscovy duck) and the highest triglyceride content in type $\alpha \mathrm{R}$ fibres in $P$. major of Pekin ducks (+16\% in comparison with the Muscovy duck). According to Guy et al. [19] and Hermier et al. [21] the four duck genotypes (Pekin, Muscovy and their crossbred, hinny and mule) used in this study presented different susceptibilities for storage of lipids in the liver or in peripheral tissues during an overfeeding period. Pekin ducks showed a much marked extrahepatic fattening and 
Muscovy ducks at the extreme exhibited the reverse situation.

\section{CONCLUSION}

The muscle typology was neither influenced by duck genotypes nor by overfeeding. By combining genotype and overfeeding effects, we were able to obtain a wide range of lipid content in muscles and to demonstrate that intramuscular fat was mainly stored in adipocytes since $63 \%$ of the variability in total lipid content of $P$. major muscle was explained by the variability in the relative surface occupied by adipocytes on muscle cross-sections. Overfeeding induced a large increase in muscle fat content in adipocytes and in type $\alpha \mathrm{R}$ fibres, only in $P$. major. Muscovy ducks displayed the lowest intramuscular fat depot and Pekin ducks the highest. For all the criteria measured in this study, except the body weight, the crossbred, hinny and mule ducks always had intermediate values to those of the parental genotypes. Intramuscular fat can influence the flavour, colour, juiciness and tenderness of meat. By comparing overfed ducks from the four genotypes, Larzul et al. [33] showed that Muscovy ducks displayed significantly higher shear force values than Pekin ducks in raw and cooked breast meat that could be related to higher cooking loss, lower lipid content, higher collagen content, lower collagen solubility and higher fibre CSA. Therefore, by using the interaction between genotype and overfeeding, it will be interesting to analyse the relationships between intramuscular fat content and the sensorial quality of meat.

\section{ACKNOWLEDGEMENTS}

We thank the Grimaud Company and particularly Bernard Retailleau for producing and providing the animals.

\section{REFERENCES}

[1] Moody WG, Cassens RG. A quantitative and morphological study of bovine longissimus fat cells. J Food Sci 1968, 33: 47-52.
[2] Gondret F, Mourot J, Bonneau M. Comparison of intramuscular adipose tissue cellularity in muscles differing in their lipid content and fibre type composition during rabbit growth. Livest Prod Sci 1998, 54: 1-10.

[3] Hood RL, Allen CE. Cellularity of bovine adipose tissue. J Lipid Res 1973, 14: 605-610.

[4] Lee YB, Kauffman RG. I. Cellular and enzymatic changes with animal growth in porcine intramuscular adipose tissue. II. Cellularity and lipogenic enzyme activities of porcine intramuscular adipose tissue. J Anim Sci 1974 38: 532-544.

[5] Rabot C. Vitesse de croissance et caractéristiques lipidiques et sensorielles des muscles de poulet. PhD thesis, INA PG, Paris, France 1998, p 156.

[6] Guy G, Hermier D, Davail S, Bely M, André JM, Hoo-Paris R. Meat production and force feeding ability of different types of ducks. In: 1st World Waterfowl Conference, Taichung Taïwan, 1-4 December, 1999, p 462-468.

[7] Hermier D, Guy G, Guillaumin S, Davail S, André JM, Hoo-Paris R. Differential channelling of liver lipids in relation to susceptibility to hepatic steatosis in two species of ducks. Comp Biochem Physiol Part B 2003, 135: 663-675.

[8] Chartrin P, Mourot J, Bernadet MD, Guy G, Duclos MJ, Baéza E. Effect of genotype and forcefeeding on the intramuscular fat deposition in duck. In: XVIth European Symposium on the Quality of Poultry Meat, St Brieuc France, 23-26 September, 2003, p 224-230.

[9] Baéza E, Marché G, Wacrenier N. Effect of sex on muscular development of Muscovy ducks. Reprod Nutr Dev 1999, 39: 675-682.

[10] Guth L, Samaha FJ. Qualitative differences between actomyosin ATPase of slow and fast mammalian muscle. Exp Neurol 1969, 25: $138-152$.

[11] Ashmore CR, Doerr L. Postnatal development of fibre types in normal and dystrophic skeletal muscle of the chick. Exp Neurol 1971, 30: 331-346.

[12] Torrella JR, Fouces V, Palomeque J, Viscor G. Capillarity and fibre types in locomotory muscles in wild Mallard ducks (Anas platyrhynchos). J Comp Physiol B 1996, 166: 164177.

[13] Buche P. Racine: un système d'analyse multiimages de coupes sériées. Application à la caractérisation de fibres musculaires. $\mathrm{PhD}$ thesis, Rennes I University, France, 1990, p 202. 
[14] Koopman R, Schaart G, Hesselink MKC. Optimisation of oil red $\mathrm{O}$ staining permits combination with immunofluorescence and automated quantification of lipids. Histochem Cell Biol 2001, 116: 63-68.

[15] Dubowitz V. In: Muscle biopsy. A practical approach. WB Saunders Company LTD, London, Philadelphia, Toronto 1985, p 707-715.

[16] Fernandez X, Meunier-Salaün MC, Ecolan P. Glycogen depletion according to muscle and fibre types in response to dyadic encounters in pigs (Sus scrofa domesticus)-relationships with plasma epinephrine and aggressive behaviour. Comp Biochem Physiol A 1994, 109: 869-879.

[17] AS. In: SAS/STAT user's guide. SAS Institute Inc, Cary, NC, 1989.

[18] Auvergne A. Facteurs de variation de la composition corporelle et tissulaire des canards avant et après gavage. $\mathrm{PhD}$ thesis, INP Toulouse, France, 1992, p 252.

[19] Babilé R. La production de foies gras de canards de Barbarie (Caïrina moschata): aspects génétiques, nutritionnels et technologiques. $\mathrm{PhD}$ thesis, INP Toulouse, France, 1989, p 315 .

[20] Zanusso J, Rémignon H, Guy G, Manse H, Babilé R. The effects of overfeeding on myofibre characteristics and metabolical traits of the breast muscle in Muscovy ducks (Caïrina moschata). Reprod Nutr Dev 2003, 43: 105115.

[21] Rémignon H, Gardahaut MF, Marché G, Ricard FH. Selection for rapid growth increases the number and the size of muscles fibres without changing their typing in chickens. J Muscle Res Cell Motility 1995, 16: 95-102.

[22] Baéza E, Dessay C, Wacrenier N, Marché G, Listrat A. Effect of selection for improved body weight and composition on muscle and meat characteristics in Muscovy ducks. $\mathrm{Br}$ Poult Sci 2002, 43: 560-568.

[23] Maxwell LC, Enwemeka CS, Fernandes G. Effects of exercice and food restriction on rat skeletal muscles. Tissue Cell 1992, 24: 491498.
[24] Brandstetter AM, Picard B, Geay Y. Muscle fibre characteristics in four muscles of growing male cattle. II. Effect of castration and feeding level. Livest Prod Sci 1998, 53: 25-36.

[25] Candek-Potokar M, Lefaucheur L, Zlender B, Bonneau M. Effect of slaughter weight and/or age on histochemical characteristics of pig longissimus dorsi muscle as related to meat quality. Meat Sci 1999, 52: 195-203.

[26] Gondret F, Lebas F, Bonneau M. Restricted feed intake during fattening reduces intramuscular lipid deposition without modifying muscle fiber characteristics. J Nutr 2000, 130: 228-233.

[27] Seideman SC, Crouse JD. The effects of sex condition, genotype and diet on bovine muscle fiber characteristics. Meat Sci 1986, 17: 55-72.

[28] Solomon MB, Lynch GP. Biochemical, histological, and palatability characteristics of young ram lambs as affected by diet and electrical stimulation. J Anim Sci 1988, 66: 19551962.

[29] Harrisson AP, Rowlerson AM, Dauncey MJ. Selective regulation of myofiber differentiation by energy status during postnatal development. Am J Physiol 1996, 270: R667R674.

[30] Ricard FH. Composition anatomique de la carcasse du canard mulard comparé aux deux types parentaux. In: Comptes rendus de la Conférence Avicole WPSA-SIMAVIP, Cahier $\mathrm{n}^{\circ} 3,1986, \mathrm{p}$ 47-64.

[31] Gille U, Salomon FV, Kattein S. Post-hatching myofibre development in the M. pectoralis of white Pekin ducks. Anat Rec 1998, 250: 154-158.

[32] Baéza E, Salichon MR, Marché G, Wacrenier $\mathrm{N}$, Dominguez B, Culioli J. Effects of age and sex on the structural, chemical and technological characteristics of mule duck meat. $\mathrm{Br}$ Poult Sci 2000, 41: 300-307.

[33] Larzul C, Imbert B, Bernadet MD, Guy G, Rémignon H. Qualité du magret dans un croisement factoriel Barbarie X INRA44. In: $5^{\mathrm{e}}$ Journées de la Recherche sur les Palmipèdes à Foie Gras, Pau (France), 9-10 October, 2002, p 29-32. 